\title{
The Effectiveness of Undercover Game Application on Students' Speaking Skill
}

\author{
Fadilah Ekayanti ${ }^{1}{ }^{*}$, Jumardin Muchtar $^{2}$ and Farida ${ }^{3}$ \\ 1,2,3Department of English Language Studies, Universitas Hasanuddin, Makassar, Indonesia \\ *fadilah.ekayanti@gmail.com
}

\begin{abstract}
The aims of this research are to determine the effectiveness of undercover game applications on students' speaking skills in terms of pronunciation and hesitation. The researchers use undercover game applications as a learning medium. The skills examined are speaking abilities, specifically pronunciation and hesitation. This study employs pre-experimental research, with a pre-test one meeting, treatment six meetings, and a post-test one meeting. This study's sample is made up of 31 students from XI IPS 1 at SMA Negeri 14 Makassar. The finding of this research is that there are improvements in students' speaking skill both in terms of pronunciation and hesitation. In terms of pronunciation, there is improvement $30 \%$ from 54.8 score in pre-test to 71.5 score in post-test. In terms of hesitation, there is improvement $31 \%$ from 53.2 score in pre-test to 70.2 score in post-test. Based on explanation the analysis above, it can be seen that there is an effectiveness of the application of undercover games in teaching speaking. It can be seen that the post-test score is higher than the pre-test. This means that the application of undercover games as learning media can improve students' speaking skills in terms of pronunciation and hesitation.
\end{abstract}

Key words: Hesitation, pronunciation, speaking, Undercover Game application.

\section{Introduction}

English as a foreign language status in Indonesia has been complemented through wide use of English in the social setting as well as the education setting. Teaching of English has been greatly emphasized by the government from elementary school up to university level. English language is one of foreign language. It becomes very important in education aspect. Because English language including to several language lesson in our country. According to Wardhaugh, there are several functions of foreign language. The first is international communication and study of language. The second is language as a system of communication. The third is the most complex of man's tool, each language is structurally different system [1].

Agustina states that for Indonesian, to understand English speaking is difficult because their mother tongue is not English. To make it easy in learning English, it has been taught since the kindergarten or playgroup level. Moreover, all of components of English language are taught integrally to achieve the integrated language skills competence. Teaching English in Indonesia focuses on the ability of communication of the students [2]. 
Based on the researcher interviewed the teacher in SMA N 14 Makassar the eleventh class, there were still many students not being able to speaking well. There were some problems that make speaking is difficulties skill. The problems were lacking of vocabulary, hesitation when they spook, missed pronunciation, they did not know about the grammar. These problems could be influence by students interesting and the used media was not suitable with students need. The lack knowledge of method and technique in teaching speaking, teacher taught speaking just give explanation and exercise without use interesting media.

The students' problem in speaking could be improved by using varieties learning media, such as card games. Undercover game application was one of them. Undercover game application is a game that uses cards and consists of two teams that are played with a minimum of 3 players, where this game has to guess who is undercover.

This research focused on undercover game application as learning media. Learning media by using games are more interesting for students to learn. This method of gamingfication results in a 20 percent increase in self-confidence, 11 percent in conceptual knowledge, 90 percent in retention of learning material, 20 percent in practical knowledge and 30 percent in task completion. Furthermore, this gamification a positive state of mind is maintained, while we can get the full attention of the students. The lessons learn through gamification also tend to last longer considering that they not only listen to the material, but also do it themselves so as to form their own experience [3].

\section{Theoritical Reviews}

\section{Definition of Speaking Skill}

Speaking is an interactive process of constructing meaning that involves producing and receiving and processing information (See a comprehensive bibliography of an interactive approach to language pedagogy) [4].

Based on definition above, the researchers concluded that speaking is the productive skill. It could not be separated from listening. When we speak we produce the text and it should be meaningful. In the nature of communication, we can find the speaker, the listener, the message and the feedback. Speaking could not be separated from pronunciation as it encourages learners to learn the English sounds.

\section{Kindsof Speaking Skill}

There are three kinds of speaking skill, they are [5]:

\section{Interactive}

Interactive is one of the speaking activities carried out by direct and indirect interaction between speakers and listeners. The teacher can ask students to take turns listening and speaking, giving each other opportunities to ask for clarification, repetition, or speech later than the conversation partner or partner.

Example: face to face conversations, daily dialogues and telephone calls

\section{Partially Interactive}

Partially interactive is one of the dominant speaking activities carried out by some people or just one person in the interaction. This activity can be done by asking one of the students to give a speech in front of the class, while the others listen and observe the speaker. The listener is also asked to respond to the speech delivered when the speech is finished.

Example: giving a speech to a live audience and sharing a presentation.

\section{Non-Interactive}

Non interactive is one of the speaking activities that there is no interaction in it, the speaker only needs to practice the fluency and accuracy of the words issued. The teacher can ask students to do assignments at home by asking them to record their own voice using English. It aims to facilitate their speaking with the correct pronunciation.

Example: when recording a speech for a radio broadcast, performing in a play, reciting a poem, singing.

\section{Definition Of Undercover Game Application}

Yosia states that the game we are playing is Undercover Game which can be installed on the App Store. In this game, there are 3 characters, namely Civilian, Undercover, and Mr White. Civilian is the protagonist character. He will get a secret word. Undercover is an antagonistic character. He will also get a secret word, but it is similar to the word Civilian. Mr White is the only character who doesn't get any words. The game can be made up of 12 people. Everyone will get their own words, but they don't know whether he is a Civilian or Undercover. Mr White, who did not get the word, would only be told that he was Mr White. After that, all will take turns to describe their respective words. Mr White also described it by guessing so it wouldn't be discovered. Then each player points to a player who might be his 
opponent. If Mr White was appointed, he would be allowed to guess what words the Civilian had. If he succeeds, he is the winner. The game continues until all civilians are eliminated or all Undercover is eliminated [6].

The countries are represented by the six colours of the colour circle: Red, Orange, Yellow, Green, Blue and Purple. During the game, players place and replace the agents adjacently to others with matching colours - the same or one of the two neighbored colours on the colour circle. Tiles can be flipped before being replaced, and later flipped again and again. Since the tiles show different colours on the sides - again two colours neighbored on the colour wheel there is a strong deduction element in the game (while younger kids rather will play it using their memory) [7].

The goal of Undercover is to get the most points. You get points by picking up point markers on one of 6 different scoring tracks. The order of the scoring marker is random and has a value between 3 and 8. Once you have picked up a tile on one track you can't pick up any more on that track. That means that being able to get the highest numbered tile as possible on each track is how you win the game. The way you move on the scoring tracks is by placing or moving tiles. The tiles are all double-sided. With one side are being the agent side and the other being the undercover side [8].

The identities of players are secret, even for players who are of the same identity. The game is played in rounds and each player has to describe the word which they received. No description of a word should be allowed more than once. At the end of each round, players would vote to eliminate 1 to 2 players (depending on the number of players) which they think are undercover [9].

The game aims to find the Undercover and eliminate them at the end of each round. The excitement is that no one knows if they are a normal player or an Undercover. That said, vague descriptions are good to hide one's identity. Yet, it may backfire as the majority may think a vague description only comes from an Undercover!

The researchers conclude that undercover game application is a game that uses cards and consists of two teams that are played with a minimum of 3 players, where this game has to guess who is that Undercover Game Application can be played essential when the player only 10 as the maximum. It is not suitable for a large class

\section{The Rules of Undercover Game Applications}

Every game has its rules to follow to keep players in the right way of playing. The undercover game application also has rules. The rules of the undercover game application, which are: Each player receives a secret word; The "Civilians" all receive the same word (e.g. "tiger"); The "Undercover" receives a slightly different word (e.g. "lion"); "Mr White" receives no word at all, and the goal is to guess other people's identities based on their descriptions of their word [10].

\section{The Benefit of Undercover Application}

There are some benefits when we play card games including undercover game applications. Haney and Helen explain the benefits of undercover game application [11], which are:

\section{Better Mental Health}

The study, which to date includes over 14,000 participants, researches health issues in the elderly. The evidence so far suggests that people who spend more time engaging in mental activities like card games may be at less risk of suffering from dementia.

\section{Improved Math Skills and Logical Thinking}

Logical thinking also plays a big part in card games. In most, you cannot rely on guesswork and instead have to think carefully about which cards the other players are holding. Challenging our minds in this way helps improve emotional and mental wellbeing.

\section{Help with Concentration, Patience and DIscipline}

Card games often involve players concentrating for hours at a time without even realising it. They become engrossed in the game and need a high level of self-control to succeed, avoiding rash decisions that could throw the game.

\section{Learn How to Cope with Losing}

Losing in cards requires composure, especially when a player has to walk away after putting in a lot of work. They learn how to move on and also how not to repeat the same mistakes. In short, it allows them to become better at turning short-term losses into long-term wins.

\section{Relax and Unwind}

For many card players, there is no better way to unwind at the end of a long day than shuffling a deck of cards and playing a few rounds of their favourite game. It is a great way to relax, regain control over the events of the day, and refocus. It's a way for people to take their minds off other things without switching on the TV. 


\section{Memory Boosting Skills}

Cards are a great way to enhance short-term memory skills. Many games involve an element of memorizing, and this can be especially helpful for older people to help keep their minds sharp. Practice makes perfect, and regularly memorizing details in a card game could even help to improve memory in real-world situations.

\section{Better Sociallife}

Card games are generally social activities, and this brings benefits for players. There is a lot of research out there on how social engagement is one of the most important factors in a happy life.

\section{Methodology}

\section{Research Design}

In this research, the researchers use pre-experimental research to know the effectiveness of undercover game applications on students' speaking skills. The researchers conduct a pre-test to know the basic knowledge of students about their speaking skills. The next step was a treatment that the researchers use the undercover game applications as learning media. At the end of the research, there was a post-test. By getting students' scores in pre-test and post-test, the significance between them was shown. The research design can be described as:

$$
\mathrm{O}_{1} \rightarrow \mathrm{X} \rightarrow \mathrm{O}_{2}
$$

Where :

$\mathrm{O}_{1}$ : pre-test

$\mathrm{X}$ : treatment

$\mathrm{O}_{2}$ : post-test

\section{Population and Sample}

The population of this research is the students from the eleventh grade of SMA Negeri 14 Makassar in the academic year 2019/2020. There were five classes of MIA (Matematika dan Ilmu Alam) consisted 30 students per class. There are five classes of IIS (Ilmu-Ilmu Sosial) consisted 30 students per class. Total students in the eleventh grade were 300 students more or less.

This research uses the purposive sampling technique. Researchers choose XI IPS 1 of SMA Negeri 14 Makassar as the sample based on the duration of treatment. Only this class is available for six meetings with pre-test and post-test. The sample of this research consisted of 31 students.

\section{Research Variable}

Variables are the object of the study that concern research. Variables divide into two, they were:

\section{Independent Variable}

The independent variable on this research is an undercover game application

\section{Dependent variable}

The dependent variable on this research is students' speaking skills which are pronunciation and hesitation as the indicators of the research.

\section{Research Instrument}

The instrument of this research is a speaking test that describes a word. It is related to the undercover game application in which every player had to guess other player identity speaking skills, pronunciation, and hesitation are the aspects that researchers focus on in this research. Every student has five minutes for each word to describe in English. This research used smartphones to record students' speaking in the class.

\section{Population and Sample}

There are several procedures to collect data in this research, they were 


\section{Pre-Test}

The pre-test is given to students to know their prior knowledge about their speaking skills, especially in pronunciation and hesitation. Each student has five minutes to describe one word in English. There is one word for each student to describe in English.

\section{Treatment}

The treatment is given to students after the pre-test. The undercover game application is used in treatment as learning media for students. The treatment procedures can be described as follow:

a The researchers explain the undercover game application.

b The researchers teach students the definition and function of the undercover game applications.

c The researchers ask the students to exercise speaking skills.

d The researchers divide students into two groups consist at least 15 students in each group.

e The researchers explain the roles and rules of the undercover game application.

$\mathrm{f}$ The students play undercover game applications in speaking to describe the word they got with instruction from researchers.

\section{Post-Test}

The post-test is given to students after the treatment. The post-test aims to know whether the significant study in students speaking skills or not. The researchers use the same method in the pre-test which students have to describe one word in five minutes. The word is different from the pre-test.

For collecting data or measure the pronunciation and hesitation of students' speaking skills, this research evaluates students' speaking in terms of pronunciation and hesitation and by using Longman's scoring profile.

Table 1. Scoring Rubric of Pronunciation

\begin{tabular}{lcl}
\hline Classification & Score & Criteria \\
\hline Excellent & $81-100$ & Pronunciation and intonation are almost always very clear/accurate. \\
Very Good & $61-80$ & Pronunciation and intonation are usually clear/accurate with a few problem areas. \\
Good & $41-60$ & Pronunciation and intonation errors sometimes make it difficult to understand the student. \\
Fair & $21-40$ & Frequent problems with pronunciation and intonation. \\
Poor & $0-20$ & The students' speak very hastily, and more sentences are not appropriate in pronunciation and \\
& & little or no communication.
\end{tabular}

Table 2. Criteria of Speaking Hesitation

\begin{tabular}{lcl}
\hline Classification & Score & Criteria \\
\hline Excellent & $81-100$ & Speaks smoothly, no hesitation does not interfere with communication. \\
Very Good & $61-80$ & Speaks smoothly, with little hesitation that does not interfere with communication. \\
Good & $41-60$ & Speaks with some hesitation, but it does not usually interfere with communication. \\
Fair & $21-40$ & Speaks with some hesitation, which often interferes with communication. \\
Poor & $0-20$ & Hesitation too often when speaking, which often interferes with communication. \\
\hline
\end{tabular}

\section{Technique of Data Analysis}

The instrument of this research is a speaking test that describes a word. It is related to the undercover game application in which every player had to guess other player identity speaking skills, pronunciation, and hesitation are the aspects that researchers focus on in this research. Every student has five minutes for each word to describe in English. This research used smartphones to record students' speaking in the class.

This research uses quantitative analysis. To measure the data, the researchers use several formulas in this research, they are:

1. Calculating the students' speaking test.

$$
\text { Score }=\frac{\text { Studentsobtainscore }}{\text { Maximalscore }(5)} \times 100
$$

2. Calculating the mean score of the students' speaking test use the following table. 


$$
X=\frac{\sum x}{N}
$$

Description :

$\mathrm{X}$ : Mean score

$\sum \mathrm{X}$ : Total sum of all scores

$N$ : The total number of sample

3. To find out improvement of percentage

$$
\%=\frac{X_{2}-X_{1}}{X_{1}} \times 100
$$

4. Calculating the value of t-test to indicate the significance between post-test and pre-test, the researcher used the formula as follow :

$$
t=\frac{D}{\sqrt{\frac{\sum D^{2} \frac{\sum D^{2}}{N}}{N(N-1)}}}
$$

Description :

$\mathrm{t}$ : Test of significance

$\mathrm{D}$ : The mean of different score

$\sum \mathrm{D}$ : The sum of the total score of significance

$\sum \mathrm{D}^{2}$ : The square of the sum for difference

$\mathrm{N}$ : The total number of subject

$\mathrm{T} \_$test $\geq \mathrm{T} \_$table, having significant influence $\mathrm{H} \_(1), v \wedge 1 \geq v \wedge 2$ or $\mathrm{P}$-value $\leq \alpha 0.05 \mathrm{~T} \_$test $\leq \mathrm{T} \_$table , having no significant influence

$H_{0}: v^{1}=v^{2}$ or $P$-value $\geq \alpha 0.05$

\section{Findings and Discussion}

The result of the data findings is that the effectiveness of undercover game applications on students' speaking skills in terms of pronunciation and hesitation is unknown.

Findings

\section{The Students' Speaking Skill in Terms of Pronunciation}

The effectiveness of undercover game application on students' speaking skill of pronunciation in SMA Negeri 14 Makassar at the result of the students' test The pre-test can be seen clearly in the following table:

Table 3. The Students' Speaking Skill in Terms of Pronunciation

\begin{tabular}{lccc}
\hline Variable & Pre-test & Post-test & Improvement \% \\
\hline Pronunciation & 54.8 & 71.5 & $30 \%$
\end{tabular}

The data shows that the score of pronunciation has improved 30\% from the mean score of pre-test 54.8to posttest 71.5. In the other part, the researchers describe the students' pre-test and post-test scores in speaking by pronunciation. They were classified into five levels of classification. They were excellent, very good, good, fair, and poor.

The classifications of the students score in pronunciation from pre-test there are $11(35 \%)$ students got fair, 11 (35\%) students got good, $9(29 \%)$ students got very good. While from the post-test there are $11(35 \%)$ students who got good, 13 (42\%) students who got very good, and 7 (23\%) students who got excellent.

\section{The Students Speaking Skill in Terms of Hesitation}

The effectiveness of undercover game application on students' speaking skill of pronunciation in SMA Negeri 14 Makassar at the result of the students' test pre-test can be seen clearly in the following table: 
Table 4. The Students' Speaking Skill in Terms of Pronunciation

\begin{tabular}{|c|c|c|c|c|c|c|}
\hline \multirow[b]{2}{*}{ No } & \multirow[b]{2}{*}{ Classification } & \multirow[b]{2}{*}{ Score Value } & \multicolumn{2}{|c|}{ PRE-TEST } & \multicolumn{2}{|c|}{ POST TEST } \\
\hline & & & $\mathrm{F}$ & $\%$ & $\mathrm{~F}$ & $\%$ \\
\hline 1 & Excellent & $81-100$ & 0 & 0 & 7 & 23 \\
\hline 2 & Very Good & $61-80$ & 9 & 29 & 13 & 42 \\
\hline 3 & Good & $41-60$ & 11 & 35 & 11 & 35 \\
\hline 4 & Fair & $21-40$ & 11 & 35 & 0 & 0 \\
\hline 5 & Poor & $0-20$ & 0 & 0 & 0 & 0 \\
\hline & & & 31 & 100 & 31 & 100 \\
\hline
\end{tabular}

Table 5. The Students' Speaking Skill in Terms of Pronunciation

\begin{tabular}{llll}
\hline Variable & Pre-test & Post-test & Improvement \% \\
\hline Hesitation & 53.2 & 70.2 & $31 \%$ \\
\hline
\end{tabular}

The score of hesitation has improved 31\% from the mean score of pre-test 53.2 to post-test 70.2 . In the other part, the researchers describe the students' pre-test and post-test scores in speaking by Hesitation. They are classified into five levels of classification. They were excellent, very good, good, fair, and poor

Table 6. Classification of the Students' Speaking Test in Terms of Hesitation Pre-Test and Post-Test

\begin{tabular}{llcccccc}
\hline & & & \multicolumn{2}{c}{ PRE-TEST } & \multicolumn{2}{c}{ POST TEST } \\
No & Classification & Score Value & F & $\%$ & & F & $\%$ \\
\hline 1 & Excellent & $81-100$ & 0 & 0 & 7 & 23 \\
2 & Very Good & $61-80$ & 9 & 29 & 10 & 32 \\
3 & Good & $41-60$ & 12 & 39 & 14 & 45 \\
4 & Fair & $21-40$ & 10 & 32 & 0 & 0 \\
5 & Poor & $0-20$ & 0 & 0 & 0 & 0 \\
\hline & & Total & & 31 & 100 & 31 & 100
\end{tabular}

The classification of the students score in hesitation from pre-test there are 10 (32\%) students got fair, 12 (39\%) students got good, $9(29 \%)$ students got very good. In pro-test there are 14 (45\%) students got good, 10 (32\%) students got very good, and 7 (23\%) students got excellent.

\section{Discussion}

\section{The Students' Speaking Skill in Terms of Pronunciation}

In the pre-test, the researchers give nine words in which students have to choose one of these words to describe. We focused on the students' pronunciation and hesitation in speaking and also give students five minutes to describe the chosen word. The purpose of this pre-test was to know students' speaking prior knowledge in terms of pronunciation and hesitation. The pronunciations of students before treatment were below the KKM (minimum standard) value which is getting a means core of 54.8. This is influenced by the mother tongue of students who are still having difficulty pronouncing a few letters in English. For example, the name of a person is one of them. Word "us" they pronounced "as", "used" they pronounced "u-set", "can" they pronounced "can" in Indonesian accent, "but" they pronounced "but" in Indonesian accent, and many words that they pronounced literally in Indonesian accent.

Another problem that made students difficult to pronounce words in English was the lack of student motivation in learning. This is evident when researchers ask students if they often speak English so that many new words students got. In the treatment of the first and second meetings, we give examples of how to describe words with good pronunciation and justify some words whose pronunciation are wrong in the pre-test. At the third meeting, the researchers use undercover game applications as learning media to find out whether this media was effective or not.

Researchers also choose undercover game applications as learning media because [12], state that the main purpose of video game applications is for entertainment and education. [13] and [15], state that games can increase student motivation. This is proven by the introduction of undercover game applications as a learning media in class making students excited to know this learning media. At the third meeting, the students' enthusiasm increased because they want to participate in playing this undercover game application. These researchers divide two groups, each consisting of fifteen people. 
[15], game instructions given by teachers must be clear. The researcher agreed with this statement because the learning process can confuse students when the instructions gave are not clear. Especially when using an undercover game application as learning media is still relatively new in the learning process. In the fourth, fifth and sixth meetings, students played undercover game applications which play by describing words in speaking. This was done to find out whether the undercover game application is effective in speaking in terms of pronunciation. The results in the post-test mean score of students were 71.5. Based on the students' mean score in the post-test is higher than the pre-test then there are improvements of $30 \%$.

\section{The Students' Speaking Skill in Term of Hesitation}

In addition to pronunciation, hesitation is the second indicator that researchers examine. The student's hesitation means score in the pre-test is 53.2. Almost all students are still repeating words because they had difficulty connecting the words.

Undercover game applications as learning media can reduce psychological stress and anxiety. This is as stated by the statement of [16], the use of appropriate games as a learning medium can reduce psychological stress and anxiety in learning English. Students were more open and also braver to talk.

Games as a learning media can increase student confidence, especially for the second language. Researchers do not fully agree because the sample in this study is 'XI IPS 1' students who learned English as a foreign language. During the treatment student anxiety was less than before treatment. The results on the post-test scores increased from the pre-test scores. The student's post-test score was 70.2 which increased by $31 \%$.

\section{Conclusion}

There is improvement in students' speaking skills using undercover game applications as the learning media. It can be shown pronunciation, students' total score in pre-test was 54.8 and in post-test was 71.5 which improved by $30 \%$.

In hesitation, students' total score in pre-test was 53.2 and in post-test 70.2 which improved by $31 \%$. The different total scores of pre-test and post-test also shown that 54 for pre-test and 70.8 for post-test. It is improved by $31 \%$ after giving the treatment.

From the explanation of the analysis of the results in tables and diagrams, it can see that there is the effectiveness of undercover game applications in teaching speaking. It can be seen that the post-test score is higher than the pre-test. It means that undercover game applications as the learning media can improve the students' speaking skills in terms of pronunciation and hesitation.

\section{References}

[1] W. Littlewood \& B.Yu. "First language and target language in the foreign language classroom". Language Teaching, https://doi.org/10.1017/S0261444809990310.2011.

[2] Sayuri "English Speaking problems of EFL Learners of Mulawarman University," 2016. Accessed: July 18, 2019. [Online] Available: https ://www . academia.edu/28545944/English_Speaking_Problems_of_EFL_Learners_ of_Mulawarman_Universiy.

[3] J. Emilia, Rachman and Eileen, "Gamification: Belajar Melalui Permainan," 2018 Accessed: July 18, 2019 [Online]. Available: https://www.experd.com/id/articles/2018/04/785/gamification-belajar-melalui-permainan. html.

[4] H.D. Brown, “Teaching by Principles: An Interactive Approach to Language Pedagogy," Englewood. 1994.

[5] Tapuih and Paja, "Jenis-Jenis Speaking dalam Bahasa inggris," 2016. Accessed: July 18, 2019. [Online]. Available: https://www.itapuih.com/2016/12/jenis-jenis-speaking-dalam-bahasa.html.

[6] Y. Yosia, "Undercover Game Application," 2017. Accessed: July 18, 2019. [Online]. Available: https://www . selasar.com/answer/34190/Manfaat-apa-yang-kamu-dapatkan-dari-permainan-Rembug-MahamerUI

[7] E. Harper, "Undercover," 2016. Accessed: January 17, 2019. [Online]. Available: https ://boardgamegeek.com/ 180570/Undercover

[8] E. Jacob and Gollander, "Tabletop Together Undercover Reviews: Undercover.2016.

[9] Williamson \& Dean, "Undercover-Game," 2017. Accessed: July 18, 2019. [Online]. Available: https ://pnwchords . com/undercover-game/.

[10] Pello and Josselin, "Undercover," 2018. Accessed: July 18, 2019. [Online]. Available: https : //www . producthunt . com/posts/undercover-2. 
[11] Haney and Helen, "The Emotional Benefits of Playing Card Games," 2018. Accessed: July 18, 2019. [Online]. Available: https://www.theemotionmachine.com/the-emotional-benefits-of-playing-card-games/.

[12] M. Peña., Noemí, \& S. Máximo, "Educational Games for Learning," 2014. Accessed: July 18, 2019. [Online]. Available: https://files.eric.ed.gov/fulltext/EJ1053979.pdf.

[13] L. Virginia, Yang, Qiaoyan., and Dixon, "Application of Games in College English Teaching in China," 2015. Accessed: July 18, 2019. [Online]. Available: https ://files .eric.ed.gov/fulltext/EJ1148758.pdf

[14] M. Christina, Steiner, R. Kickmeier, \& D. Michael, "Undercover: Non-Invasive, Adaptive Interventions in Educational Games, 2009 Accessed: July 18, 2019. [Online]. Available: https://www.researchgate.net/profile/Elke_Mattheiss/publication/228994100_Undercover_ Noninvasive_adaptive_interventions_in_educational_games/links/0fcfd5084f597b46e3000000/

Undercover-Non-invasive-adaptive-interventions-in-educational-games.pdf?origin=publication_detail.

[15] L. Virginia, Yang, Qiaoyan., and Dixon, "Application of Games in College English Teaching in China," 201.5 Accessed: July 18, 2019. [Online]. Available: https ://files . eric.ed.gov/fulltext/EJ1148758.pdf

[16] S. Kenneth \& Horowitz, "The Effect of Massive Multiplayer Online Video Games on the Willingness to Communicate and Communicative Anxiety of College Students in Puerto Rico," 2019. Accessed on July $18,2019$. [Online]. Available: https://files.eric.ed.gov/fulltext/EJ1220304.pdf 